Pacific Journal of Mathematics

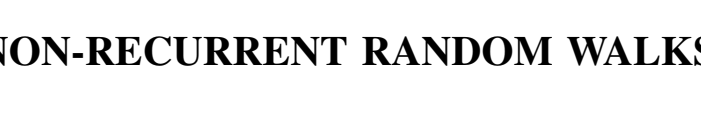




\title{
NON-RECURRENT RANDOM WALKS
}

\author{
K. L. Chung and C. Derman ${ }^{1}$
}

Introduction and Summary. Let $\left\{X_{i}\right\} \quad i=1,2, \cdots$ be a sequence of independent and identically distributed integral valued random variables such that 1 is the absolute value of the greatest common divisor of all values of $x$ for which $P\left(X_{i}=x\right)>0$. Define

$$
S_{n}=\sum_{i=1}^{n} X_{i}
$$

Chung and Fuchs [5] showed that if $x$ is any integer, $S_{n}=x$ infinitely often or finitely often with probability 1 according as $E X_{i}=0$ or $\neq 0$, provided that $E\left|X_{i}\right|<\infty$. Let $0<E X_{i}<\infty$, and $A$ denote a set of integers containing an infinite number of positive integers. It will be shown that any such set $A$ will be visited infinitely often with probability 1 by the sequence $\left\{S_{n}\right\} n=1,2, \cdots$. Conditions are given so that similar results hold for the case where $X_{i}$ has a continuous distribution and the set $A$ is a Lebesgue measurable set whose intersection with the positive real numbers has infinite Lebesgue measure.

A Theorem about Markov Chains. Let $\left\{Z_{n}\right\}, n=0,1, \cdots$ denote a Markov chain with stationary transition probabilities where each $Z_{n}$ takes on values in an abstract state space $\boldsymbol{X}$. The distribution of $Z_{0}$ is given but arbitrary. Let $\Omega$ denote the space of all possible sample sequences $w, P$ the probability measure over $\Omega$ and $P(\cdot \mid \cdot)$ the conditional probability. The following theorem appears in [4].

Theorem 1. Let $A$ be any event in $\boldsymbol{X} . A$ sufficient condition that

$$
P\left(Z_{n} \in A \text { infinitely often }\right)=1
$$

is

$$
\inf _{z \in X} P\left(Z_{n} \in A \text { for some } n \mid Z_{0}=z\right)>0 .
$$

Since [4] is not readily accessible, we shall prove the theorem here.

Proof. ${ }^{2}$ We have with probability 1 that for $j \geqq N$

Received April 23, 1955 and in revised form August 1, 1955. Work supported in part by the United States Air Force through the office of Scientific Research of the Air Research and Development Command under contract AF 18 (600)-760.

1 Now at Columbia University.

2 The proof given here is a modification of one suggested by J. Wolfowitz. 


$$
\begin{aligned}
& P\left(Z_{n} \in A \text { for some } n \geq N \mid Z_{0}=z_{0}, \cdots, Z_{j}=z_{j}\right) \\
& \geqq P\left(Z_{n} \in A \text { for some } n>j \mid Z_{0}=z_{0}, \cdots, Z_{j}=z_{j}\right) \\
& =P\left(Z_{n} \in A \text { for some } n \mid Z_{0}=z_{j}\right)
\end{aligned}
$$

using the Markovian and stationarity properties. As $j \rightarrow \infty$ the left member of (3) approaches with probability 1 the characteristic function $b_{N}$ of the event

$$
B_{N}=\left\{Z_{n} \in A \text { for some } n \geqq N\right\}
$$

(see Doob [8, p. 332]). The right member of (3) is bounded below by a positive number on account of (2). Hence $b_{N}=1$ with probability 1 ; that is, $P\left(B_{N}\right)=1$. This being true for all $N$ we have

$$
P\left(\lim _{N \rightarrow \infty} B_{N}\right)=\lim _{N \rightarrow \infty} P\left(B_{N}\right)=1 .
$$

But $\lim _{N \rightarrow \infty} B_{N}$ is the event that $Z_{n} \in A$ infinitely often. This proves the theorem.

If $\boldsymbol{X}$ has only a denumerable number of states and if all the states belong to the same class (that is, for every pair of states $i$ and $j$ there exists integers $n_{1}$ and $n_{2}$ such that $\left.P\left(Z_{n_{1}}=j \mid Z_{0}=i\right) P\left(Z_{n_{2}}=i \mid Z_{0}=j\right)>0\right)$ it can be easily seen that (2) is both a necessary and sufficient condition for (1). In fact, the probability in (2) must be 1 for all states $z .^{3}$

Sums of lattice random variables. Let $\left\{X_{i}\right\} \quad i=1,2, \cdots$ be a sequence of independent and identically distributed integral valued random variables such that 1 is the absolute value of the greatest common divisor of all values of $x$ for which $P\left(X_{i}=x\right)>0$. Consider the sequence $\left\{S_{n}\right\} \quad n=0,1, \cdots$, where we set $S_{0}=0$ with probability 1 and

$$
S_{n}=S_{0}+\sum_{i=1}^{n} X_{i}
$$

The sequence $\left\{S_{n}\right\}$ is then a Markov chain with stationary transition probabilities and a denumerable state space. Because the transition probabilities are stationary, we shall simply write

$$
P\left(S_{n+m}=i \mid S_{n}=j\right)=P\left(S_{m}=i \mid S_{0}=j\right)
$$

even though $S_{0}=0$ with probability 1 .

We now state as lemmas some known results to be used below.

Lemma 1. Let $\left\{Z_{n}\right\} n=0,1, \cdots$ be a Markov chain with a denumerable state space. If $\sum_{n=1}^{\infty} P\left(Z_{n}=j \mid Z_{0}=i\right)<\infty$ for all $i$ and $j$, then

\footnotetext{
3 We are indebted to J. Wolfowitz for this remark.
} 


$$
P\left(Z_{n}=j \text { for som? } n \mid Z_{\lrcorner}=i\right)=\begin{gathered}
\sum_{n=1}^{\infty} P\left(Z_{n}=j \mid Z_{0}=i\right) \\
1+\sum_{n=1}^{\infty} P\left(Z_{n}=j \mid Z_{0}=j\right)
\end{gathered} .
$$

When $E X_{i}=\mu>0$, a result of Chung and Fuchs [5] implies that

$$
\sum_{n=1}^{\infty} P\left(S_{n}=j \mid S_{0}=i\right)<\infty
$$

for all $i$ and $j$. Therefore, on replacing $Z_{n}$ by $S_{n}$ in (4) and noting that $P\left(S_{n}=j \mid S_{0}=j\right)=P\left(S_{n}=0 \mid S_{\jmath}=0\right)$ we have

$$
P\left(S_{n}=j \text { for some } n \mid S_{0}=i\right)=\frac{\sum_{n=1}^{\infty} P\left(S_{n}=j \mid S_{0}=i\right)}{1+\sum_{n=1}^{\infty} P\left(S_{n}=0 \mid S_{0}=0\right)}
$$

Lemma 1 is a special case of a relation given by Doeblin [7] (see Chung [3]). However, we shall sketch a direct proof.

Proof. We define $P\left(Z_{0}=j \mid Z_{0}=j\right)=1$. Then we have

(6) $\quad P\left(Z_{n}=j \mid Z_{0}=i\right)=\sum_{m=1}^{n} P\left(Z_{m}=j, Z_{r} \neq j\right.$ for

$$
\begin{aligned}
& \left.1 \leqq r<m \mid Z_{j}=i\right) P\left(Z_{n}=j \mid Z_{m}=j\right) \\
= & \sum_{m=1}^{n} P\left(Z_{m}=j, Z_{r} \neq j \text { for } 1 \leqq r<m \mid Z_{0}=i\right) P\left(Z_{n-m}=j \mid Z_{0}=j\right)
\end{aligned}
$$

On summing over $n$ in (6) and interchanging summations on the right we get

$$
\begin{aligned}
& \sum_{n=1}^{\infty} P\left(Z_{n}=j \mid Z_{0}=i\right)=\sum_{n=1}^{\infty} P\left(Z_{m}=j, Z_{r} \neq j\right. \text { for } \\
& 1 \leq r<m)\left(1+\sum_{n=1}^{\infty} P\left(Z_{n}=j \mid Z_{0}=j\right)\right) \\
& =P\left(Z_{n}=j \text { for some } n\right)\left(1+\sum_{n=1}^{\infty} P\left(Z_{n}=j \mid Z_{0}=j\right)\right),
\end{aligned}
$$

the relation (4).

LEMMA 2. If $E X_{i}=\mu>0$, then

$$
\begin{array}{rlrl}
\lim _{j \rightarrow \infty} \sum_{n=1}^{\infty} P\left(S_{n}=j \mid S_{0}=i\right) & =\frac{1}{\mu}>0, & \mu<\infty \\
& =0, & & \mu=+\infty .
\end{array}
$$

Lemma 2 is due to Chung and Wolfowitz [6]. We now prove the following. 
Theorem 2. (i) If $0<E X_{i}=\mu<\infty$ and $A$ is any set containing an infinite number of positive integers, then $S_{n} \in A$ infinitely often with probability 1.

(ii) If $E X_{i}=+\infty$, then there exists a set $A$ containing an infinite number of positive integers such that $S_{n} \in A$ only finitely often with probability 1.

Proof of (i). Since $0<\mu<\infty$, by (8) there exists a constant $c>0$, independent of $i$, and an integer $J(i)$ such that for all $j>J(i)$

$$
\sum_{n=1}^{\infty} P\left(S_{n}=j \mid S_{0}=i\right)>c .
$$

Therefore by $\left(4^{\prime}\right)$ and (5)

$$
P\left(S_{n}=j \text { for some } n \mid S_{0}=i\right)>\frac{c}{1+c^{\prime}}, \quad j>J(i)
$$

where $c^{\prime}=\sum_{n=1}^{\infty} P\left(S_{n}=0 \mid S_{0}=0\right)<\infty$. Since $A$ contains infinitely many positive integers, it always contains an integer greater than $J(i)$ for every $i$. Therefore (2) holds and part (i) of Theorem 2 follows from Theorem 1.

Proof of (ii). If $\mu=+\infty$, then from (8) there exists an increasing subsequence $\left\{i_{j}\right\}$ of positive integers such that

$$
\sum_{j=1}^{\infty} \sum_{n=1}^{\infty} P\left(S_{n}=i_{j} \mid S_{0}=0\right)=\sum_{n=1}^{\infty} \sum_{j=1}^{\infty} P\left(S_{n}=i_{j} \mid S_{0}=0\right)<\infty .
$$

Let $A=\left\{i_{y}\right\}$. Now (11) is the expected number of $n$ such that $S_{n} \in A$. Since this expectation is finite it follows that the number of $n$ such that $S_{n} \in A$ is finite with probability 1 . This completes the proof of the theorem.

Random variables with continuous distribution functions. Consider now a sequence $\left\{X_{i}\right\} \quad i=1,2, \cdots$ of independent, identically distributed random variables possessing a common density function $f(x)$. Again let $\left\{S_{n}\right\} \quad n=0,1, \cdots$ denote the cumulative sums $S_{n}=S_{0}+\sum_{i=1}^{n} X_{i}$ where $S_{0}=0$ with probability 1 . Our previous remark pertaining to the notation $P\left(\cdots \mid S_{0}=x\right)$ applies here also. Suppose $E X_{i}=\mu>0$. Then a result of Chung and Fuchs [5] implies that $H(x)=\sum_{n=1}^{\infty} P\left(S_{n} \leqq x\right)<\infty$ for all $x$. Since $H(x)$ is non-decreasing, $H^{\prime}(x)$ exists everywhere except on a set $N_{0}$ of Lebesque measure zero. Let 


$$
\begin{aligned}
h(x) & =H^{\prime}(x) & & x \notin N, \\
& =1, \text { say, } & & x \in N, x \geq 0 \\
& =0 & & x \in N, x<0
\end{aligned}
$$

We shall say that $f(x)$ satisfies condition $I$ if there exist constants $K_{1}$ and $K_{2}$ such that

$$
0<K_{1} \leqq \lim _{x \rightarrow \infty} h(x) \leqq \varlimsup_{x \rightarrow \infty} h(x) \leqq K_{2}<\infty
$$

and if

$$
\lim _{x \rightarrow-\infty} h(x)=0
$$

The behavior of $h(x)$ for large $|x|$ has been investigated in various papers on renewal theory. Smith [10], for example, has shown that if $f(x)=0$ for $x<0, f(x) \rightarrow 0$ as $|x| \rightarrow \infty$ and $f(x) \varepsilon L_{1+\delta}$ for some $\delta>0$, then

$$
\begin{aligned}
\lim _{x \rightarrow \infty} h(x) & =\frac{1}{\mu}, & & \mu<\infty \\
& =0, & & \mu=+\infty
\end{aligned}
$$

More recently, Smith $^{4}$ has shown that the condition that $f(x)=0$ for $x<0$ may be dropped, and furthermore (13) holds. We now prove the following.

Lemma 3. If $E X_{i}=\mu<\infty, f(x)$ satisfies condition $I, A$ is any Lebesgue measurable set of positive real numbers having infinite measure, then

$$
\inf _{-\infty<x<\infty} P\left(S_{n} \in A \text { for some } n \mid S_{0}=x\right)>0 \text {. }
$$

Proof. For every $x$, let $A_{x}$ be a measurable subset of $A$ with $0<c_{1}<m\left(A_{x}\right)<c_{:}<\infty$ and such that for a given number $L_{1}$ all points in $A_{x}$ exceed $x$ by at least $L_{1}$. Such a set exists since $m(A)=\infty$. For any $\varepsilon>0$ it follows from (12) that there exists an $L_{1}=L_{1}(\varepsilon)$ such that

$$
0<(1-\varepsilon) K_{1} c_{1}<\sum_{n=1}^{\infty} P\left(S_{n} \in A_{x} \mid S_{0}=x\right)<(1+\varepsilon) K_{2} c_{2}<\infty .
$$

Let $A_{x}^{\prime}$ be any measurable set with $m\left(A_{x}^{\prime}\right) \leqq c_{2}$ and such that for a given $L_{2}$ all points in $A_{x}^{\prime}$ are exceeded by $x$ by at least $L_{2}$. By $(13)^{5}$ there exists an $L_{2}=L_{2}(\varepsilon)$ such that

$$
\sum_{n=1}^{\infty} P\left(S_{n} \in A_{x}^{\prime} \mid S_{0}=x\right)<\varepsilon .
$$

4 Communication by letter.

5 Added in proof: Condition (13) can be dropped; (16) follows from the fact that $\lim _{x \rightarrow-\infty} H(x)=0$ whether (13) holds or not. 
Let $L=\max \left(L_{1}, L_{2}\right)$. For a given $y \in A_{x}$ let $A_{x y}^{1}=A_{x} \cap[y-L, y+L)$, $A_{x y}^{2}=A_{x} \cap[y+L, \infty)$ and $A_{x y}^{3}=A_{x} \cap(-\infty, y-L)$.

Then from (15) and (16)

$$
\begin{aligned}
\sum_{n=1}^{\infty} P & \left(S_{n} \in A_{x} \mid S_{0}=y\right)=\sum_{n=1}^{\infty} P\left(S_{n} \in A_{x y}^{1} \mid S_{0}=y\right) \\
& +\sum_{n=1}^{\infty} P\left(S_{n} \in A_{x y}^{2} \mid S_{0}=y\right)+\sum_{n=1}^{\infty} P\left(S_{n} \in A_{x y}^{3} \mid S_{0}=y\right) \\
& \leqq \sum_{n=1}^{\infty} P\left(-L<S_{n}<L \mid S_{0}=0\right)+K_{2} c_{2}(1+\varepsilon)+\varepsilon .
\end{aligned}
$$

The first term on the right of (17) is finite by the result of Chung and Fuchs [5]. Therefore, since (17) is true for all $y \in A_{x}$ we have

$$
\sup _{y \in A_{x}} \sum_{n=1}^{\infty} P\left(S_{n} \in A_{x} \mid S_{0}=y\right)<c_{3}<\infty
$$

Let $F_{x}^{(v)}(B)=P\left(S_{v} \in B, S_{v^{\prime}} \notin A_{x}\right.$ for $\left.1 \leqq v^{\prime}<v \mid S_{0}=x\right)$ where $B$ is any measurable subset of $A_{x}$. Define $P\left(S_{0} \in A_{x} \mid S_{0}=y\right)=1$ if $y \in A_{x}$ and $=0$ otherwise. Then we have

$$
\begin{aligned}
& \sum_{n=1}^{N} P\left(S_{n} \in A_{x} \mid S_{0}=x\right)= \sum_{n=1}^{N} \sum_{v=1}^{n} \int_{A_{x}} P\left(S_{n} \in A_{x} \mid S_{v}=y\right) F_{x}^{(v)}(d y) \\
&=\sum_{v=1}^{N} \int_{A_{x}} \sum_{n=v}^{N} P\left(S_{n} \in A_{x} \mid S_{v}=y\right) F_{x}^{(v)}(d y) \\
& \leqq \sum_{v=1}^{N} \int_{A_{x}} \sum_{n=0}^{\infty} P\left(S_{n} \in A_{x} \mid S_{0}=y\right) F_{x}^{(v)}(d y) \\
& \leqq \sum_{v=1}^{N} F_{x}^{(v)}\left(A_{x}\right) \sup _{y \in A_{x}} \sum_{n=0}^{\infty} P\left(S_{n} \in A_{x} \mid S_{v}=y\right) \\
& \leqq P\left(S_{n} \in A_{x} \text { for some } n \mid S_{0}=x\right)\left(1+c_{3}\right) .
\end{aligned}
$$

This being true for all $N$ the lemma follows on account of (15).

We now state the following.

Theorem 3. (i) If $0<E X_{i}=\mu<\infty$, Condition I is satisfied, and $A$ is any Lebesgue measurable subset of the positive real numbers, then $S_{n} \in A$ infinitely often or finitely often with probability 1 according as $m(A)=\infty$ or $<\infty$.

(ii) If $\mu=\infty$, then there exists a measurable subset $A$ of the positive real numbers with $m(A)=\infty$ such that $S_{n} \in A$ for only finitely many $n$ with probability 1.

Proof of (i). If $m(A)=\infty$, the result follows from Theorem 1 and Lemma 3. If $m(A)<\infty$ it follows from (15) that $\sum_{n=1}^{\infty} P\left(S_{n} \in A\right)<\infty$. 
Since that is the expected number of $n$ such that $S_{n} \in A$, the assertion follows immediately.

Proof of (ii). A result due to Blackwell [1] asserts that for any fixed $d>0$.

$$
\lim _{y \rightarrow \infty} \sum_{n=1}^{\infty} P\left(y \leqq S_{n} \leqq y+d\right)=0 .
$$

Using this result the rest of the proof is similar to that of part (ii) Theorem 2.

Unsolved problems. Let $\left\{X_{i}\right\}$ be a sequence of independent and identically distributed $r$-dimensional random vectors, $S_{n}=\sum_{i=1}^{n} X_{i}, B$ be any Borel set in the $r$-dimensional Euclidean space $R^{r}$. It has been recently proved by Hewitt and Savage [9] (in the lattice case also by Blackwell [2]) that the probability that $S_{n} \in B$ infinitely often is necessarily either 0 or 1 . It would be of interest to determine for which sets the probability is 0 , and for which the probability is 1 . Our results give a criterion for this dichotomy in certain cases in $R^{1}$, namely in the lattice case where $E X_{i}$ exists and is finite (Theorem 2) and in the continuous case under more restrictive conditions (Theorem 3).

\section{REFERENCES}

1. D. Blackwell, Extension of a renewal theorem, Pacific J. Math., 3 (1953), 315-320.

2. _._. On transient Markov processes with a countable number of states and stationary transition probabilities, to appear in Ann. Math. Statist.

3. K. L. Chung, Contributions to the theory of Marlevv chains, J. Res. Nat. Bur. Standards, 50 (1953), 203-208.

4. Lecture notes on the theory of Markov chains, Columbia University Graduate Math. Statistices Soc., (1951).

5. K. L. Chung, and W. H. J. Fuchs, On the distribution of values of sums of random variables, Mem. Amer. Math. Soc., (1951).

6. K. L. Chung, and J. Wolfowitz, On a limit theorem in renewal theory, Ann. of Math., 55 (1952), 1-6.

7. W. Doeblin, Sur deux problèms de M. Kolmogoroff concernant les chaines dénombrables, Bull. Soc. Math. France, 66 (1938), 210-220.

8. J. L. Doob, Stochastic processes, New York, 1953.

9. E. Hewitt, and L. J. Savage, Symmetric measures on cartesian products, to appear in Trans. Amer. Math. Soc.

10. W. L. Smith, Asymptotic renewal theorems, Proc. Roy. Soc. Edinburgh, Sect. A, 64 (1954), 9-48.

SYRACUSE UNIVERSITY 



\section{PACIFIC JOURNAL OF MATHEMATICS}

\section{EDITORS}

\author{
H. L. Royden \\ Stanford University \\ Stanford, California \\ E. Hewitt \\ University of Washington \\ Seattle 5 , Washington
}

R. P. Dilworth

California Institute of Technology

Pasadena 4, California

\author{
A. HorN* \\ University of California \\ Los Angeles 24, California
}

\section{ASSOCIATE EDITORS}

\author{
E. F. BECKENBACH \\ C. E. BURGESS \\ H. BUSEMANN \\ H. FEDERER
}

\author{
M. HALL \\ P. R. HALMOS \\ V. GANAPATHY IYER \\ R. D. JAMES
}

\author{
M. S. KNEBELMAN \\ I. NIVEN \\ T. G. OSTROM \\ M. M. SCHIFFER
}

J. J. STOKER

G. SZEKERES

F. WOLF

K. YOSIDA

\section{SPONSORS}

\author{
UNIVERSITY OF BRITISH COLUMBIA \\ CALIFORNIA INSTITUTE OF TECHNOLOGY \\ UNIVERSITY OF CALIFORNIA, BERKELEY \\ UNIVERSITY OF CALIFORNIA, DAVIS \\ UNIVERSITY OF CALIFORNIA, LOS ANGELES \\ UNIVERSITY OF CALIFORNIA, SANTA BARBARA \\ MONTANA STATE UNIVERSITY \\ UNIVERSITY OF NEVADA \\ OREGON STATE COLLEGE \\ UNIVERSITY OF OREGON \\ UNIVERSITY OF SOUTHERN CALIFORNIA
}

STANFORD RESEARCH INSTITUTE

STANFORD UNIVERSITY

UNIVERSITY OF UTAH

WASHINGTON STATE COLLEGE

UNIVERSITY OF WASHINGTON

AMERICAN MATHEMATICAL SOCIETY HUGHES AIRCRAFT COMPANY SHELL DEVELOPMENT COMPANY

Mathematical papers intended for publication in the Pacific Journal of Mathematics should be typewritten (double spaced), and the author should keep a complete copy. Manuscripts may be sent to any of the editors. Manuscripts intended for the outgoing editors should be sent to their successors. All other communications to the editors should be addressed to the managing editor, Alfred Horn at the University of California, Los Angeles 24, California.

50 reprints of each article are furnished free of charge; additional copies may be obtained at cost in multiples of 50 .

The Pacific Journal of Mathematics is published quarterly, in March, June, September, and December. The price per volume (4 numbers) is $\$ 12.00$; single issues, $\$ 3.50$. Back numbers are available. Special price to individual faculty members of supporting institutions and to individual members of the American Mathematical Society: $\$ 4.00$ per volume; single issues, $\$ 1.25$.

Subscriptions, orders for back numbers, and changes of address should be sent to Pacific Journal of Mathematics, c/o University of California Press, Berkeley 4, California.

Printed at Kokusai Bunken Insatsusha (International Academic Printing Co., Ltd.), No. 10, 1-chome, Fujimi-cho, Chiyoda-ku, Tokyo, Japan.

* During the absence of E. G. Straus.

PUBLISHED BY PACIFIC JOURNAL OF MATHEMATICS, A NON-PROFIT CORPORATION COPYRIGHT 1956 BY PACIFIC JOURNAL OF MATHEMATICS 


\section{Pacific Journal of Mathematics}

\section{Vol. 6, No. $3 \quad$ BadMonth, 1956}

Richard Arens and James Eells, Jr., On embedding uniform and topological spaces ............................................ 397

N. Aronszajn and Prom Panitchpakdi, Extension of uniformly continuous transformations and hyperconvex metric spaces .............. 405

Kai Lai Chung and Cyrus Derman, Non-recurrent random walks ........ 441

Harry Herbert Corson, III, On some special systems of equations . . . . . . . . . 449

Charles W. Curtis, On Lie algebras of algebraic linear transformations . . . 453

Isidore Heller, Neighbor relations on the convex of cyclic permutations . . . . 467

Solomon Leader, Convergence topologies for measures and the existence of transition probabilities..................................... 479

D. H. Lehmer, On certain character matrices ...................... 491

Michael Bahir Maschler, Minimal domains and their Bergman kernel function ........................................... 501

Wm. M. Myers, Functionals associated with a continuous transformation ................................... 517

Irving Reiner and Jonathan Dean Swift, Congruence subgroups of matrix groups ....................................... 529

Andrew Sobczyk, Simple families of lines ................... 541

Charles Standish, A class of measure preserving transformations ........ 553 Jeremiah Milton Stark, On distortion in pseudo-conformal mapping ..... 565 